\section{Are Jupiter's Cloud-belts due to Solar Heat?}

A CIRCUMSTANCE which, so far as I know, has not yet been noticed, seems to me to afford very strong evidence in favour of my theory that the cloud-belts of Jupiter are caused by heat existing in the planet itself. If the cloud-belts were caused by solar heat, they should exhibit a characteristic corresponding to what is observed in the case of the earth's equatorial cloud-zone. "At the equator," Kämtz remarks, "the sun nearly always rises in a clear sky ; towards mid-day the heavens are clouded; towards evening the clouds disperse." Now it follows that to an observer regarding the earth as we see Jupitex, there would appear at all times only a fragment of an equatorial belt, near the niddle of the disc. But the belts of Jupiter present no such fragmentary appearance; there is a change in their aspect close by the edge of the disc, but the change is one obviously arising from the foreshortening.

A nother circumstance also is worth noting. If the cloudbelts of the outer planets were sun-raised, the great tropical belt of Saturn ought to follow the sun as the tropical calm zone of the earth does. The fact that the Saturnian belt remains persistently equatorial is very significant. RICFrD. A. PROCTOR

\section{The Rotundity of the Earth}

IN your number for July Ith, after publisling an ex parte statement, you ask, "Will nothing stop Parallax's mouth?" I hope you will allow me to say, in your next issue, that only one thing can operate in doing so! That one thing is a practical experiment fairly conducted, honestly reporter, and logically appliecl. Your readers will notice that although my sigurature (Parallax) is appended to the "copy of agreement," it does not appear in the "copy of certificate," and it is proper they should know the reason. It had been agreed that the flags should be fixed in my presence, and that the spirit-level employed should be in good working order anu to my satisfaction in every respect. On arriving at the "scene of operations" at the appointed time, I found that the flags had been fixed, and that the spiritlevel had been adjusted for some time before my arrival. I inmediately protested, and demanded that $I$ and the friends with me should go and measure the altitude of each flag, but an obstinate resistance was offered to this, and also to any interference with the adjustment of the "level." I therefore at once clecliner to be longer present, and returned to Norwich, where the whole matter was exposed at a public meeting. Notwithstanding the manifest injustice of the attempt, and my refusal to have anything to do with it the moment I discovered its unfairness, these wise and clever and very just Newtonians would have the world believe that they had once and for ever settled the question of the earth's true form and magnitude. Such tricks are innworthy of the cause, and the men who can conclescend to deal in them can do no real service to the school to which they belong.

I beg to give the friends of the Newtonian system the following simple challenge: To select six miles of still water, place a boat at one end, with a flag say six feet above the surface of the water. Now, at the other end, let a good telescope be fixed at an elevation of eighteer inches; I affirm that the boat and its flag will be distinctly visible; whereas, if the earth is a globe of 8 , ooo miles diameter, the top of the flag would be more than seven feet below the intervening arc of water. This is my challenge, and let the Newtonians decide that it shall be accepted saying with me, "let us stand or fall by the result!"

I, Hawley Villas, Chalk Farm Road, London, July is

Paraliax

[We print "Parallax's" letter, but we warn everybody against accepting his challenge. Mr. Wallace's treatment at the hands of these gentry shows us what to expect. Let "Parallax" take a good telescope and a return ticket to some seaside place and watch the ships travelling to and fro over the horizon. We offer him space in NATURE to detail his observations, and to explain them, if he can, on any other theory than the received one.-ED.]

\section{Eclipse of the Moon}

THE eclipse of Thesday evening ( $($ uly 12 ) exhibited some interesting variations in tint and degree of illumination in different parts or the shadow. There seems to have been a dark spot, perhaps half the moon's diameter, about the centre of the umbra, nearly, if not quite, free from refracted light; outsicte this a ruddy zone; and beyond this again, to the edge of the shadow, a region strongly illuminated, comparatively speaking, with yellowish pink, as it appeared when projected upon the entering, or yellowish green upon the emerging moon. It is true that just after the commencement, and some little time before the end of the eclipse, the part just within the shadow appeared darker than the eclipsed limb; but this, I think, must have been an optical effect caused by the overpowering light of the uneclipsed portion.

When, however, about two-thirds or three-quarters of the moon's suxface was covered, both before and after totality, the illumination of the umbra near its boundary was very conspicuous. The "seas" reflected less light than the other portions, and the regions along the sonth limb, and between the north limb and Mare Imbrium, were specially bright. These gave almost the effect of the illuminated cusps of the moon being distorted, and prolonged into the shadow. When the eclipse became total, the eastern hemisphere, about the region of Oceanus Procellarnus, was covered by a dark shade, so dark that the extreme eastern limb was scarcely if at all visible. A short time after totality the moon was quite lidden by clouds, and remained so, excepting occasional momentary glimpses, during which nothing could be seen, excepting that she was visible as a dull, pinkish light, till just before the end of the total phase, when the clouds broke away from her neiglibourhcod in a marvellonsly dramatic way. The emerging was wonderfully beautiful; first a strong, greenish light appeared along the eastern limb; this changed to silvery; then bright, full yellow. The eclipsed part was moderately bright, shining with a reddish light, excepting a deeper shade orer the western hemisphere. In fact, the appearance was exactly analogous to that at the commencement of totality. I regretted extremely that I had not the opportunity of watching whether the dark spot really traversed the disc from sicle to side, but I have little doubt that at the time of central cclipse the moon presented a well-marked amular phase.

As the gathering of clouds, and their sudden dispersion at the end of the total phase, seems a striking instance of the supvosed influence of moonlight in dissipating vapour, it is perhaps well to mention that after the end of the eclipse, clouds appeared to be again gathering round the moon.

The telescope I used was a $3 \frac{1}{2}$-inch refractor, armed with a power of 35 .

Cardiff, July $\mathrm{x} 7$

Geo. C. ThOMPSON

\section{Wave-lengths of Complementary Colours}

IN applying Mr. Maxwell's observations to the verification of a hypothesis (see NATURe for July 7), Mr. Murphy identifies complementary colours by their mames, overlocking the fact that the observations themselves afford pretty accurate determinations of several pairs. Separate results are given for two observers in Tables VI. and IX. of the memoir formerly cited by Mr. Murphy (NATURE, April 28), and are laid down grapluically in figures 4 and 5. From the latter form of the data, as the more convenient, though no cloubt the less accurate, the following formula was obtained by interpolation, for the relation letween complementary wave-lengths :--

$$
(\lambda-L)\left(L^{\prime}-\lambda^{\prime}\right)=M^{2}
$$

where $\lambda$ is a wave-length between 2350 and 2100 (in Fraunhofer's measuxe); $\lambda^{\prime}$ is its complementary between $r 820$ ank x 700 ; and $L, L^{\prime}, M$ are quantities differing for different eyes, and having the values
2076
1842
$2132 \cdot 5$
$1859 \%$
$77^{\circ} 9$
for observer "K ;"

Mr. Murphy's complementaries are not in general really complementary for either observer. Independently of this, Mr. Murphy's probable error is about 53, that is, over one in 100: the probable error of the formula is certainly under one in 500 , between the limits stated.

C. J. MONRO

\section{THE APPLICATION OF PHOTOGRAPHY TO} MILITARY PURPOSES

M ODERN warfare may in many respects be considered as so many applications of science. Not only is war matériel designed and manufactured nowadays upon 